Leben Schreiben 
Christa Bürger

\title{
Leben Schreiben
}

\author{
Die Klassik, \\ die Romantik \\ und der Ort der Frauen
}

Mit 22 Abbildungen

J.B. Metzlersche Verlagsbuchhandlung Stuttgart 
CIP-Titelaufnahme der Deutschen Bibliothek

Bürger, Christa :

Leben Schreiben : Die Klassik, die Romantik und der

Ort der Frauen. - Stuttgart : Metzler, 1990

ISBN 978-3-476-00681-3

ISBN 978-3-476-03297-3 (eBook)

DOI 10.1007/978-3-476-03297-3

Dieses Werk einschließlich aller seiner Teile ist urheberrechtlich geschützt. Jede Verwertung außerhalb der engen Grenzen des Urheberrechtsgesetzes ist ohne $\mathrm{Zu}$ stimmung des Verlages unzulässig und strafbar. Das gilt insbesondere für Vervielfältigungen, Übersetzungen, Mikroverfilmungen und die Einspeicherung und Verarbeitung in elektronischen Systemen.

(C) 1990 Springer-Verlag GmbH Deutschland

Ursprünglich erschienen bei J.B. Metzlersche Verlagsbuchhandlung und Carl Ernst Poeschel Verlag GmbH in Stuttgart 1990 


\section{INHALT}

\section{Vorbemerkung}

Seite VII

I.

Charlotte von Kalb: Eine Auslöschung

Seite 1

Selbstentwertung

Bilder

Trauer

II.

"Dilettantism Der Weiber"

Seite 19

III.

Sophie Mereau oder die sinnliche Gewissheit

Seite 33

"Symbolisierende Einbildungskraft"

"Das Blütenalter der Empfindung"

Todesarten

IV.

Johanna Schopenhauer oder die Entsagung

Seite 53

Teetisch

"Gabriele« 
V.

Luziferische Rhapsodien. Carolines Briefwerk

Seite 81

Kleine Formen

Innere Gewißheit

VI.

ICH RAHEL

Seite 109

"Defizit"

Anerkennung

Leben

VII.

Bettina/Bettine - die Grenzgängerin

Seite 133

Zerrissenheit

Der Weg zum Sozialen

Das Kind Bettine

VIII.

Leben Schreiben. Stationen weibligher

SelbSTVERGEWISSERUNG

Seite 159

ANmerkungen

Seite 175 
Aus den Ausgrenzungsgeschichten, die ich erzählen wollte, ist eine Geschichte weiblicher Selbstvergewisserung geworden, die mich zwingt, meinen Ort innerhalb der Literaturwissenschaft neu zu bestimmen. Die Literaturwissenschaft hat Gegenstände, aber sie hat sich selbst nicht. Sie kann nicht darstellen, wie sie in der Sprache sich bewegt. Das vergessene Schreiben, dem ich mich zugewendet hatte, war mir nicht ein Gegenstand. Ich wollte in Erfahrung bringen, wie ich schreiben mußte, um es zum Sprechen zu bringen. Ich wollte, daß mein Schreiben jenes Schreiben als Subjekt wiederherstellt. Das erklärt die Uneinheitlichkeit der Zugänge in diesem Buch. Denn das Schreiben, das mir aus seiner Vergangenheit entgegentritt, hält nicht gleichen Abstand. Es setzt der Annäherung unterschiedliche Widerstände entgegen. Es bestimmt selbst die Grenze, wo es aufhört und ich anfange.

Dem Schreiben der Frauen, die sich kenntlich zu machen suchten, ist Undeutlichkeit wesentlich, weil es sich vom Leben nicht trennen will. Ich habe diesem Schreiben eine Kenntlichkeit zu geben versucht, die es in seiner Undeutlichkeit erkennbar macht. Ich habe zu vergessen versucht, was ich als Literaturwissenschaftlerin davon wußte. Es kam mir darauf an, das Hervorbringen dieses Schreibens nachzuschreiben, doch ohne mich selbst unkenntlich zu machen.

Die Literaturwissenschaft, die über ihre Gegenstände immer schon hinaus ist, weiß, daß sie es mit Trivialliteratur zu tun hat, unberührt von der Trivialität ihres Arguments, das so alt ist wie das Schreiben, an dem es Herrschaft ausübt. In einem 1811 im Morgenblatt für gebildete Stände veröffentlichten fiktiven Gespräch am Teetisch läßt Varnhagen von Ense einen jungen Herrn auf die Frage, ob er die Schriftstellerin, über die man sich unterhält, gelesen habe, die boshaft naive Antwort geben: "Ich habe sie nicht gelesen; aber ist denn das nöthig, um sie zu beurtheilen? « Warum es nicht nötig ist, weiß er auch. Um seine Meinung zu demonstrieren, erzählt er das 
»Gleichnis vom Raben«: »Wie hoch er sich auch schwingt, und das entwendete Gold im Fluge trägt, man weiß doch, daß es ihm nicht angehört, daß er es aus Liebe zum Glanze irgendwo weggenommen«!

Feministische Literaturwissenschaft weiß, daß es eine verdrängte Geschichte gibt, aber diese ist ihr noch ein Gegenstand. Ihren Gegenstand will sie sich deutlich machen, indem sie ihn entweder als "Leben « oder als »Werk« betrachtet. Der heimliche Positivismus einer Frauenliteraturgeschichte, in der literarische Kritik und Biographie gleichsam nebeneinander herlaufen, wiederholt, ohne es zu wissen und zu wollen, das Ausgrenzungsurteil der "großen« Geschichte. Denn die Versuche, das Schreiben, von dem hier die Rede ist, zum »Werk« zu machen oder seine Bedeutung auf ein »Leben« zu verschieben, lassen sich auf das wirkliche Ganze nicht ein, das gerade in der Undeutlichkeit von Leben Schreiben zur Erscheinung kommt.

Wenn aber Undeutlichkeit die Bestimmtheit dieses Schreibens ist, so ist in ihm ein Einspruch wirksam, der dessen Ungleichzeitigkeit begründet und der es zugleich - für mich, für uns - in seine eigene Bildungsgeschichte einsetzt. Der herrschende Diskurs, den ich unter dem Stichwort des "Dilettantism der Weiber « zitiere, legt fest, was als "Werk" gelten darf und was als Nicht-Kunst ausgegrenzt wird. Was so unterschiedliche Schriftstellerinnen wie Charlotte von Kalb und Rahel Varnhagen, Sophie Mereau und Bettina von Arnim, Caroline Schlegel-Schelling und Johanna Schopenhauer miteinander verbindet, ist die stillschweigende Weigerung, die Trennung von Kunst und Leben, wie der herrschende Diskurs sie im Namen der Kunstautonomie verfügt, anzuerkennen. Indem sie ihren kulturellen Tod nicht scheuen, gewinnen sie die Freiheit, schreibend sich selbst als ein anderes Subjekt hervorzubringen. Die Verweigerungsenergie aber, die auf die Aufhebung der Trennung von Kunst und Leben drängt, wirkt fortan im Innern des Diskurses selber. 


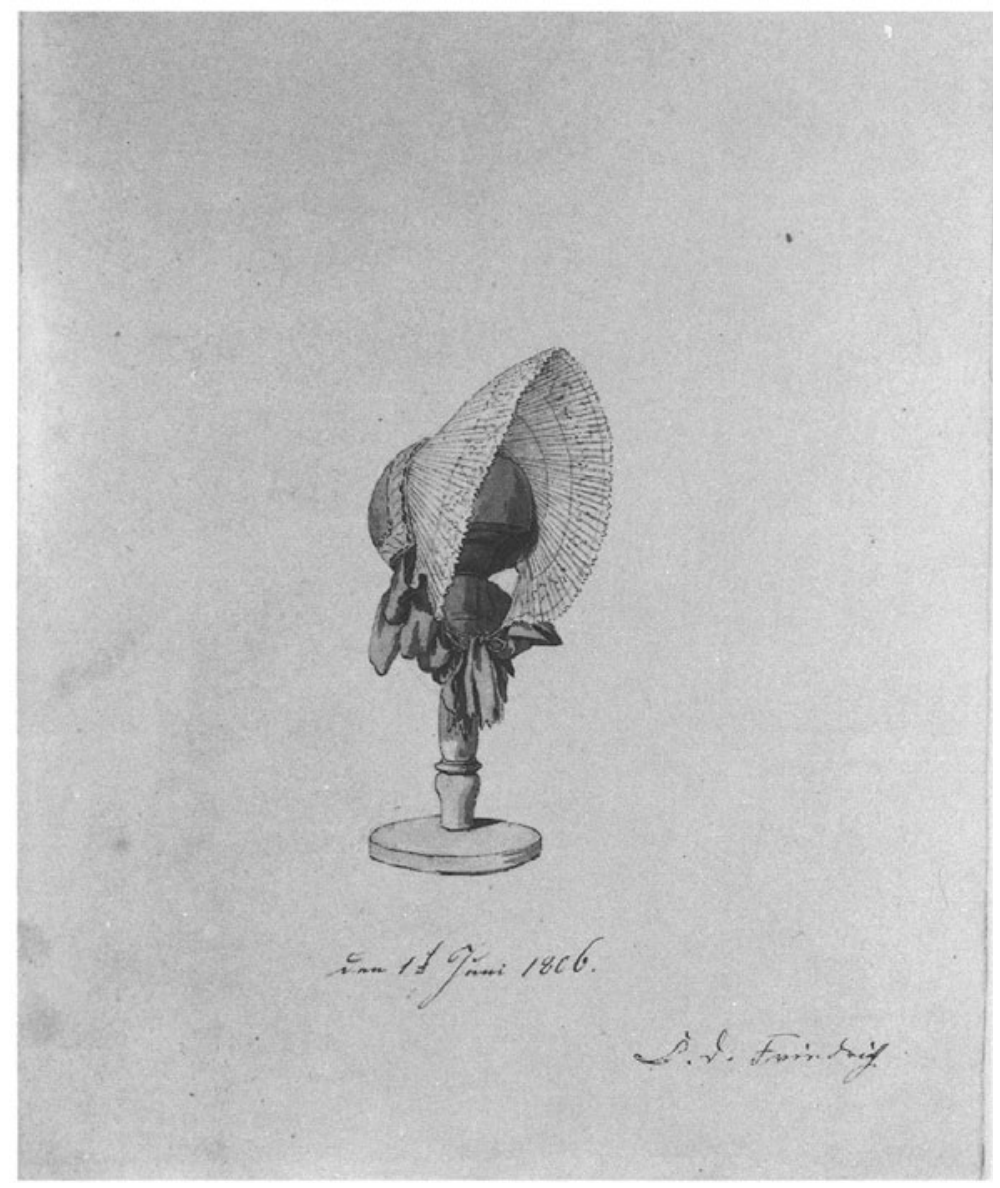

Caspar David Friedrich, Frauenhaube auf einem Ständer, Federzeichnung, 1806. Hamburg, Kunsthalle. 